\title{
Non-Tuberculous Mycobacteria: Seven-Year Experience of a Tertiary Hospital
}

\author{
Micobactérias Não-Tuberculosas: Experiência de Sete \\ Anos de um Hospital Terciário
}

\author{
Nuno Ferreira MONTEIRO $\rrbracket^{1}$, Susana PERES ${ }^{2}$, Kamal MANSINHO ${ }^{2}$ \\ Acta Med Port 2019 Mar;32(3):208-213 - https://doi.org/10.20344/amp.10932
}

\section{ABSTRACT}

Introduction: Non-tuberculous mycobacteria are ubiquitous organisms. Precise determination of infection numbers is difficult, since reporting them to public health departments is frequently not mandatory; furthermore, isolating a non-tuberculous mycobacteria does not necessarily translate into disease. The aims of this study were to ascertain non-tuberculous mycobacteria data of a tertiary hospital, determine the incidence and approach to colonization versus disease, and the incidence of predisposing comorbidities.

Material and Methods: Retrospective study in a tertiary hospital, involving patients with positive cultural exam for non-tuberculous mycobacteria in any biological sample, from 2010 to 2017.

Results: A total of 125 non-tuberculous mycobacteria isolates was identified, corresponding to 96 patients. Of these, $57.4 \%$ were male $(n=54)$; median age was 65 years (interquartile range $=[50-82])$. From these, $60.7 \%(n=57)$ had some degree of immunosuppression, most frequently due to malignant tumour $(49.0 \%)$ or HIV infection $(39.2 \%)$. It was found that 29 patients $(31.0 \%)$ had structural respiratory tract changes. Colonization was defined in $65.6 \%$ of patients $(n=63)$. While $71.0 \%$ of non-tuberculous mycobacteria infections were pulmonary, the remaining $29.0 \%$ presented as disseminated. According to available clinical records, $60.6 \%(n=20)$ of the presumably infected patients fulfilled American Thoracic Society diagnostic criteria for non-tuberculous mycobacteria disease.

Discussion: Several cases of non-tuberculous mycobacteria infection in this study presented as life-threatening, multi-systemic disease, highlighting the importance of accurate diagnosis and timely treatment. Other cases of presumed infection might instead have corresponded to colonization, possibly resulting in futile therapy.

Conclusion: While there are diagnostic criteria for treatment of non-tuberculous mycobacteria infections, no such guidelines exist to assess colonization. One of the most challenging aspects remains the correct differentiation between colonization and early-stage infection.

Keywords: Mycobacterium Infections, Nontuberculous/epidemiology; Nontuberculous Mycobacteria; Portugal

\section{RESUMO}

Introdução: Micobactérias não-tuberculosas são organismos ubiquitários. A determinação precisa de incidência e prevalência de infecções por estes agentes é difícil, uma vez que na maioria dos países não são de declaração obrigatória e o isolamento de micobactérias não-tuberculosas não traduz obrigatoriamente a presença de doença. Os objectivos do estudo foram a avaliação dos dados epidemiológicos e abordagem de micobactérias não-tuberculosas num hospital terciário, determinar a incidência de colonização versus infecção, e a presença de comorbilidades.

Material e Métodos: Estudo retrospetivo num hospital terciário envolvendo doentes com exame cultural positivo para micobactérias não-tuberculosas em qualquer amostra biológica, de 2010 a 2017.

Resultados: Foram isoladas 125 micobactérias não-tuberculosas, correspondendo a 96 doentes. Destes, 57,4\% era do sexo masculino ( $n=54)$; a mediana de idade era 65 anos [50 - 82], 60,7\% encontrava-se imunossuprimidos, mais frequente tumor maligno (49,0\%) ou infeção por vírus da imunodeficiência humana $(39,2 \%)$. Vinte e nove doentes $(31,0 \%)$ apresentavam alterações estruturais crónicas da árvore traqueo-brônquica. Colonização assintomática foi identificada em $65,6 \%$ dos doentes $(n=63)$. Do total da amostra, $71,0 \%$ das infeções por micobactérias não-tuberculosas era pulmonar, e os restantes $29,0 \%$ disseminada. De acordo com os registos clínicos disponíveis, 60,6\% ( $n=20)$ das infeções presumidas preenchia critérios de diagnóstico da American Thoracic Society.

Discussão: Foram identificados vários casos de infeção multi-sistémica grave, sublinhando a importância do diagnóstico e tratamento adequados e atempados. Paralelamente, foram também descritos casos de infeção presumida que poderão ter correspondido apenas a colonizações assintomáticas.

Conclusão: Enquanto se encontram publicados critérios de diagnóstico de infeção por micobactérias não-tuberculosas, tal não acontece até à data para avaliar colonizações. Assim, um dos aspectos mais desafiantes da gestão destes casos é a correcta diferenciação entre colonização assintomática e infeção em fase inicial.

Palavras-chave: Infecções por Micobactérias Não-Tuberculosas/epidemiologia; Micobactérias Não-Tuberculosas; Portugal

\section{INTRODUCTION}

Nontuberculous mycobacteria (NTM) were first described in the late $19^{\text {th }}$ century, ${ }^{1}$ but were not recognized as potential human pathogens until the 1930 s, and only attained widespread clinical relevance in the second half of the $20^{\text {th }}$ century, first in patients with structural lung disease and later with the advent of human immunodeficiency vi- rus (HIV) infection and severely immunocompromised patients. ${ }^{2}$ They were first referred to as 'atypical', 'unusual', 'unclassified' or 'anonymous mycobacteria' prior to their current denomination. ${ }^{3,4}$

NTM are ubiquitous organisms in the environment, and can be isolated from water, soil, plants, and animals. ${ }^{5,6}$

1. Department of Internal Medicine II. Hospital Egas Moniz. Centro Hospitalar de Lisboa Ocidental. Lisbon. Portugal.

2. Department of Infectious Diseases. Hospital Egas Moniz. Centro Hospitalar de Lisboa Ocidental. Lisbon. Portugal.

$\triangle$ Autor correspondente: Nuno Ferreira Monteiro. nferreiramonteiro@gmail.com

Recebido: 11 de junho de 2018 - Aceite: 14 de novembro de 2018| Copyright $\odot$ Ordem dos Médicos 2019 
Interestingly, the highest rates of NTM colonization in potable water systems have been found in hospitals, haemodialysis clinics and dental offices. Human-to-human transmission has not been documented. ${ }^{7}$

Based on their growth rate in culture, these bacteria can also be classified as slow, intermediate or rapid growers. Human disease is suspected to be acquired from environmental exposure - when inhaled or ingested by susceptible individuals (for example, chronic obstructive lung disease or bronchiectasis), infection can lead to a chronic, progressive and sometimes fatal disease. ${ }^{8}$ While $90 \%$ of cases involve the pulmonary system, disease can also develop in other locations, namely skin, soft tissue, bones, lymph nodes or appear as disseminated. ${ }^{9}$

Precise determination of NTM infection numbers is difficult, since reporting these infections to public health departments is not mandatory in the majority of countries, contrary to tuberculosis. Furthermore, simply isolating a NTM does not necessarily translate into disease, making the detection of these isolates a poor surrogate for disease prevalence. However, a yearly increase in NTM disease prevalence (between $2 \%$ to $8.5 \%$ per year) has been described in recent years in a multitude of surveys in the overall population. ${ }^{10}$ The annualised prevalence of NTM lung disease within four integrated healthcare delivery systems in the USA ranged from 1.4 to 6.6 per 100 000. Similarly, other studies conducted in Australia, Canada, the Netherlands and Taiwan reported increases in the incidence or prevalence of NTM. Also, pulmonary NTM hospitalisations increased significantly between 1998 and 2005, according to another study involving 11 states in the USA. ${ }^{8}$ Increased awareness of the disease, improved culture and radiographic techniques, and the increasing utility of molecular techniques could partly explain this global increase in NTM prevalence. ${ }^{4}$ A true increase in incidence could be related to changes in the host such as an aging population or an increased prevalence of structural lung disease. ${ }^{8}$

Portugal is an endemic region for Mycobacterium tuberculosis infection, whereas NTM infection is sometimes overlooked or misinterpreted as tuberculosis during an initial assessment, until culture results (which can take several weeks to be obtained) become available. Also, for the reasons described above, there is a significant lack of controlled data regarding disease prevalence in this country as well; there is a scarcity of epidemiological data published in recent years, focusing on the incidence or prevalence of NTM isolates or infection in Portugal, particularly in immunocompromised patients or disseminated disease presentations - these few recently published studies focus primarily on patients followed in outpatient appointments, with chronic pulmonary disease, where a minority was diagnosed and treated for NTM lung disease. .11,12 $^{12}$

From an epidemiological standpoint the aims of this study were to ascertain NTM data of a tertiary hospital by quantifying and identifying all NTM isolates over a period of seven years, both from inpatients admitted to a ward as well as outpatients followed in consultation.

From a clinical standpoint, the aims of this study were to determine the incidence of colonization versus clinically significant disease, the approach to each of these diagnoses, as well the incidence of predisposing comorbidities for NTM disease in this population.

\section{MATERIAL AND METHODS}

Retrospective study conducted in a tertiary hospital, involving every patient with a positive cultural exam for NTM over a period of seven years, detected in any biological samples collected both during infirmary admission and outpatient consultation appointments. Detailed isolate results were provided by the hospital's Microbiology Unit, and patients' available medical data was collected from their respective clinical records. NTM disease was diagnosed based on the American Thoracic Society (AMT) clinical case definition. ${ }^{3,13}$ The only patients excluded from this study were those with unspecified Mycobacterium spp isolates.

A descriptive analysis of data was performed in which categorical variables were presented as proportions/percentages and continuous variables as median, interquartile range, mean and standard deviation where applicable. Continuous variables were compared by a Student $t$ test or the Mann-Whitney $U$ test, while categorical variables were compared by the chi-square test or Fisher exact test. Statistical significance was defined as $p<0.05$. Data analysis was conducted using Statistical Package for Social Sciences - SPSS ${ }^{\circledR}$ version 20.0 for Windows ${ }^{\circledR}$.

Table 1 - Patients' sociodemographic and clinical data

\begin{tabular}{|c|c|c|}
\hline \multicolumn{2}{|l|}{ Patients, $\mathrm{n}$} & 96 \\
\hline \multicolumn{2}{|c|}{ Age (years), median [interquartile range] } & $65[50-82]$ \\
\hline \multirow[t]{2}{*}{ Gender, n (\%) } & Male & $54(56.2 \%)$ \\
\hline & Female & $42(43.8 \%)$ \\
\hline \multirow[t]{4}{*}{ Immunosuppression, n (\%) } & Malignant neoplasm & $25(20.0 \%)$ \\
\hline & Human immunodeficiency virus infection & $20(16.0 \%)$ \\
\hline & Pharmacological immunomodulation & $5(4.0 \%)$ \\
\hline & Haemodialysis & $1(0.8 \%)$ \\
\hline \multirow[t]{2}{*}{ Structural lung disease } & No & $70(72.9 \%)$ \\
\hline & Yes & $26(27.1 \%)$ \\
\hline
\end{tabular}




\section{RESULTS}

Over the course of seven years, 125 NTM isolates were identified in several different biologic samples, corresponding to 96 patients. Of these, $57.4 \%$ were male ( $n=54)$, and the age median was 65 years (interquartile range $=[50-$ 82]).

Within the total number of patients, $60.7 \%(n=57)$ had some degree of immunosuppression. Of these, the cause for immunosuppression was a malignant tumour in $49.0 \%$, HIV infection in $39.2 \%$ [ $85 \%$ of which diagnosed as Centers for Disease Control and Prevention (CDC) stage C3, with TCD4+ lymphocyte count median of 45 cells/ $\mu \mathrm{L}]$, immunosuppressive drugs in $9.8 \%$ and haemodialysis in $2.0 \%$. Also, $31.0 \%$ patients $(n=29)$ presented significant structural respiratory tract changes confirmed by computerized tomography (CT) scans, either due to chronic obstructive pulmonary disease or pulmonary neoplasm (Table 1).

Mycobacterial culture requests were issued by a variety of different medical specialties and in distinct settings: among the most frequent were Pulmonology Consultation (37.6\%), Infectious Diseases Infirmary (26.4\%), Pulmonology Infirmary (8.0\%), Internal Medicine Infirmary (4.0\%), Infectious Diseases Consultation (3.2\%) and Nephrology/ Renal Transplant Consultation (2.4\%).

According to clinical observation registries, colonization was assumed in $65.6 \%$ of patients $(n=63)$, whereas the remaining were presumptively diagnosed with NTM infection (34.4\%, $n=33$ ), of which $71 \%$ was exclusively pulmonary and the remaining $29.0 \%$ presented as disseminated (all of which in severely immunocompromised HIV patients). Within the group of patients with infection, 60.6\% ( $n=20)$ fulfilled ATS diagnostic criteria for NTM disease and initiated treatment in an Infectious Diseases infirmary. The remaining $39.4 \%(n=13)$, who were under follow-up by Pulmonology, were directed to out-of-hospital specialized clinics for initiation of treatment after isolation of NTM (clinical records were insufficient regarding fulfilment of diagnostic criteria in these patients).

When comparing patients with NTM isolates from hospital admissions versus outpatient appointments, the prevalence of immunosuppression was significantly higher in inpatients ( $c=0.23, p=0.03$ ), as was the prevalence of disseminated NTM infections ( $c=0.45, p=0.01)$. The causes

Table 2 - Biological samples positive for NTM culture

\begin{tabular}{lc}
\hline Biological samples, $\mathbf{n}(\%)$ & $\mathbf{1 2 5}(\mathbf{1 0 0} \%)$ \\
\hline Sputum & $71(58.7 \%)$ \\
Bronchoalveolar lavage & $33(27.3 \%)$ \\
Urine & $7(5.8 \%)$ \\
Blood & $7(5.8 \%)$ \\
Bone marrow & $2(1.6 \%)$ \\
Deep wound exudate & $2(1.6 \%)$ \\
Liver specimen & $1(0.8 \%)$ \\
Pleural effusion & $1(0.8 \%)$ \\
Gastric fluid & $1(0.8 \%)$ \\
\hline
\end{tabular}

Table 3 - Mycobacterial isolates

\begin{tabular}{lc}
\hline Slow-growing mycobacteria, $\mathbf{n}(\%)$ & \\
\hline M. gordonae & $37(29.6 \%)$ \\
M. avium complex (MAC) & $35(28.0 \%)$ \\
M. kansasii & $8(6.4 \%)$ \\
M. lentiflavum & $6(4.8 \%)$ \\
M. xenopi & $3(2.4 \%)$ \\
M. mucogenicum & $3(2.4 \%)$ \\
M. bovis & $3(2.4 \%)$ \\
M. szulgai & $2(1.6 \%)$ \\
M. genavense & $2(1.6 \%)$ \\
M. canariasens & $2(1.6 \%)$ \\
M. peregrinum & $2(1.6 \%)$ \\
M. gastri & $1(0.8 \%)$ \\
\hline Fast-growing mycobacteria, $\mathbf{n}(\%)$ & \\
\hline M. fortuitum & $7(5.6 \%)$ \\
M. chelonae & $5(4.0 \%)$ \\
M. abscessus & $1(0.8 \%)$ \\
\hline
\end{tabular}

of immunosuppression were also significantly different between inpatients and outpatients, with considerably higher prevalence of late-stage HIV infections in the former and malignant neoplasms in the latter ( $c=0.55, p=0.03$ ).

The organic samples where NTM were isolated were sputum $(58.4 \%, \mathrm{n}=73)$, bronchoalveolar lavage fluid $(28.0 \%, n=35)$, urine $(5.6 \%, n=7)$, blood $(3.2 \%, n=4)$, bone marrow $(1.6 \%, n=2)$, liver biopsy $(0.8 \%, n=1)$, deep wound exudate $(0.8 \%, n=1)$, pleural effusion $(0.8 \%, n=1)$ and gastric fluid $(0.8 \%, n=1)$ (Table 2$)$.

The most frequent NTM isolates among all biological samples were M. gordonae (29.6\%, $\mathrm{n}=37)$, Mycobacterium avium complex (MAC) $(28.0 \%, \mathrm{n}=35)$, M. kansasii $(6.4 \%$, $\mathrm{n}=8)$, M. fortuitum $(5.6 \%, \mathrm{n}=7)$, M. lentiflavum $(4.8 \%, \mathrm{n}=$ $6)$ and $M$. chelonae $(4.0 \%, n=5)$ (Table 3).

Within the group of infected patients, the most frequent agents were MAC in $39.4 \%$ of cases $(n=13), M$. gordonae in $12.1 \%(n=4)$ and M. kansasii in $12.1 \%(n=4)$. There was no statistically significant association between the prevalence of certain NTM species in the presence of structural lung disease $(p=0.223)$ or immunosuppression of any kind $(p=0.286)$ (Table 4).

There were no documented cases of patients co-infected with NTM and M. tuberculosis.

\section{DISCUSSION}

The slight male predominance in our sample is in line with worldwide data regarding gender ratios in NTM colonization and infection. Historically, male gender has been considered a risk factor for NTM lung disease and males continue to make up the majority of patients in most areas, ${ }^{13}$ however, some studies conducted in countries like the United States of America (specifically in the state of Oregon) and South Korea have actually registered a female predominance. The reason for this shift remains mostly 
Table 4 - Mycobacterial isolate distribution according to HIV diagnosis and disease presentation

\begin{tabular}{|c|c|c|c|c|}
\hline \multirow[t]{2}{*}{ Mycobacterial isolate (n) } & \multicolumn{2}{|c|}{$\begin{array}{l}\text { Human Immunodeficiency Virus (HIV) } \\
\text { infection, } \mathbf{n}(\%)\end{array}$} & \multicolumn{2}{|c|}{$\begin{array}{l}\text { Disease presentation, } \\
\mathrm{n}(\%)\end{array}$} \\
\hline & Yes & No & Pulmonary & Disseminated \\
\hline M. gordonae (37) & $4(20.0 \%)$ & $33(31.4 \%)$ & $4(18.2 \%)$ & $0(0.0 \%)$ \\
\hline M. avium complex (35) & $8(40.0 \%)$ & $27(25.7 \%)$ & $7(31.8 \%)$ & $6(66.7 \%)$ \\
\hline M. kansasii (8) & $0(0.0 \%)$ & $8(7.6 \%)$ & $3(13.6 \%)$ & $2(22.2 \%)$ \\
\hline M. fortuitum (7) & $2(10.0 \%)$ & $5(4.8 \%)$ & $1(4.5 \%)$ & $0(0.0 \%)$ \\
\hline M. lentiflavum (6) & $0(0.0 \%)$ & $6(5.7 \%)$ & $1(4.5 \%)$ & $0(0.0 \%)$ \\
\hline M. chelonae (5) & $0(0.0 \%)$ & $5(4.8 \%)$ & $1(4.5 \%)$ & $0(0.0 \%)$ \\
\hline M. xenopi (3) & $2(10.0 \%)$ & $1(1.0 \%)$ & $2(9.1 \%)$ & $0(0.0 \%)$ \\
\hline M. mucogenicum (3) & $0(0.0 \%)$ & $3(2.9 \%)$ & $0(0.0 \%)$ & $0(0.0 \%)$ \\
\hline M. bovis (3) & $0(0.0 \%)$ & $3(2.9 \%)$ & $0(0.0 \%)$ & $0(0.0 \%)$ \\
\hline M. szulgai (2) & $1(5.0 \%)$ & $1(1.0 \%)$ & $0(0.0 \%)$ & $1(11.1 \%)$ \\
\hline M. genavense (2) & $2(2.0 \%)$ & $0(0.0 \%)$ & $1(4.5 \%)$ & $0(0.0 \%)$ \\
\hline M. canariasens (2) & $0(0.0 \%)$ & $2(1.9 \%)$ & $1(4.5 \%)$ & $0(0.0 \%)$ \\
\hline M. peregrinum (2) & $0(0.0 \%)$ & $2(1.9 \%)$ & $0(0.0 \%)$ & $0(0.0 \%)$ \\
\hline M. gastri (1) & $0(0.0 \%)$ & $1(1.0 \%)$ & $0(0.0 \%)$ & $0(0.0 \%)$ \\
\hline M. abscessus (1) & $0(0.0 \%)$ & $1(1.0 \%)$ & $0(0.0 \%)$ & $0(0.0 \%)$ \\
\hline
\end{tabular}

unexplained; however, genetics may play a role, since many females who develop bronchiectasis and NTM infection share a similar body type - tall slender status, frequent pectus excavatum, kyphoscoliosis and mitral valve prolapse, all risk factors implicated in increased NTM infection incidence. $^{8}$

NTM are often saprophytes and, in many cases, they colonize airways rather than infect them. ${ }^{4}$ It is known that NTM are significantly less pathogenic than M. tuberculosis; as such, they often require some degree of host impairment to cause disease - be it an immunocompromised status or structural lung damage. ${ }^{8}$ In the studied sample, over $60 \%$ of patients presented with some degree of immunosuppression, while almost one third had documented conformational changes of the respiratory tract, which could represent important risk factors for disease.

This dichotomy, however, brings to light a possible diagnostic shortcoming. Both the ATS and British Thoracic Society (BTS) have published sets of diagnostic criteria to support the treatment of NTM clinical infections, 3,11,14 based on symptom presentation, radiological findings and bacterial isolates; Portugal's national guidelines refer mostly to the ATS criteria. ${ }^{15}$ The difficulty arises in the definition, or lack thereof, of NTM colonization and its effective differentiation from early-stage disease. Indeed, during diagnostic workup, in many cases, the isolation of an NTM from the respiratory tract poses a problem rather than providing a solution; the likelihood of sputum contamination by environmental mycobacteria is high, and can result in misattribution of clinical significance to the finding. ${ }^{5}$ As of this article's writing, no substantial agreement exists regarding the significance of colonization; some authors consider it to be a non-pathogenic condition, while others interpret it as a potential initial phase of NTM disease, which would warrant treatment. ${ }^{16}$ At present, a correct assessment of this clinical significance is estimated to accompany no more than $30 \%$ of NTM isolations. ${ }^{5}$ In light of this, and paired with limited clinical records for consultation, it can only be inferred that some, if not most, of the patients identified in the present study who were directed to outpatient clinics for initiation of treatment might not have gathered criteria for antimycobacterial therapy. We cannot determine whether or not treatment was effectively started in these clinics upon patients' arrival, as we had no access to clinical data from these centres. We could confirm, however, that all patients whose treatment was started in the Infectious Diseases infirmary did gather ATS diagnostic criteria for NTM infection; in these cases, the antimycobacterial regimens employed were selected in accordance to the most-recently published national guidelines. ${ }^{13}$

In agreement with most published data, patients in this study presented most frequently with exclusively pulmonary disease; however, the overall relative prevalence of NTM lung disease is estimated to be around $90 \%,{ }^{9}$ whereas in our case, it amounted only to $70 \%$; this was due to a comparatively high incidence of disseminated infections in the studied sample (nearly $30 \%$ of all diagnoses), in a subgroup of severely immunocompromised patients due to HIV infection and very low TCD4+ cell counts (invariably < $100 \mathrm{cel} /$ $\mu \mathrm{L})$.

Regarding the frequency of NTM isolates and their association with disease, this study's findings corroborate the data of most other publications on the topic. The most common NTM responsible for human infection is MAC which are most frequently found in pulmonary disease. ${ }^{17}$

The number of $M$. kansasii isolates and their role in disease in this study were comparatively higher than what has been suggested in other publications regarding 
epidemiological distribution of mycobacteria: it has been reported that in Europe, infections caused by M. xenopi and, particularly in Scandinavian countries and in Great Britain, those caused by $M$. malmoense, are very frequent, whereas in the United States of America, infections caused by $M$. kansasii are much more prevalent. 5,18,19 In this study, however, the overall incidence of $M$. kansasii was considerably high, only below M. gordonae and MAC species.

Also noteworthy is the number of $M$. gordonae isolates that was interpreted in the context of active infection; $M$. gordonae is a less common NTM pathogenic species, often being considered a colonizing mycobacterium with little association to disease..$^{8,20-22}$ However, in the present study, $M$. gordonae was the third most frequently identified mycobacteria in patients deemed infected.

Our findings regarding presentation and comorbidity differences between inpatients and outpatients were in accordance with our expectations and are explained by the severity of immunosuppression in admitted patients, who often require urgent hospitalization and present with more serious manifestations of NTM disease than those followed routinely in outpatient consultations.

There are some limitations in this study. Notably, the lack of access to medical data recorded in outpatient clinics, especially pertaining to treatment options, leaves us unable to comment on the adequacy of these decisions. Also, the scarcity of some hospital records, particularly in cases when patients were referred to these outpatient clinics, made it difficult to ascertain the clinical pertinence of these referrals. Finally, this study was carried out in a single center, and one should be careful about generalisation of the results to other institutions with different settings.

\section{CONCLUSION}

This study calls to attention the significant prevalence of NTM infections, particularly in specific high-risk populations; in our study it presented as a multi-systemic, life-threatening condition in nearly $30 \%$ of all cases, with marked prevalence in severely immunocompromised patients. However, it also serves to highlight the importance of adequately employing diagnostic tools to readily distinguish between NTM infection and colonization, helping physicians decide who to treat - in our study, only around $60 \%$ of patients deemed infected fulfilled ATS diagnostic criteria according to available records, which might have resulted in an overestimation of NTM infection and possibly futile treatments.

One of the most challenging aspects of managing patients with NTM isolates is drawing the line between NTM colonization and early stage infection; advances in this area could help prevent unnecessary treatments for patients who are simply colonized, as well as prevent loss of sight of the real cause of disease. In countries where M. tuberculosis is endemic, the number of requested mycobacterial cultures is understandably greater, which results in overall higher numbers of NTM detection. However, NTM reporting is not yet mandatory in many countries and, as such, detailed clinical records are fundamental in streamlining diagnostic workup and treatment choices in patients who are considered infected. These records would also be useful in providing reliable, quantifiable data regarding NTM disease numbers in regards to incidence, prevalence, disease manifestations and outcome.

\section{ACKNOWLEDGEMENTS}

The authors would like to thank Judite Baptista for her collaboration in providing microbiological isolate data for our analysis.

\section{PROTECTION OF HUMANS AND ANIMALS}

As a retrospective study, informed consent was not required by the Hospital's ethics committee for approval.

\section{DATA CONFIDENTIALITY}

The authors declare having followed the protocols in use at their working center regarding patients' data publication.

\section{CONFLICTS OF INTEREST}

All authors report no conflict of interest.

\section{FUNDING SOURCES}

This research received no specific grant from any funding agency in the public, commercial, or not-for-profit sectors.

\section{REFERENCES}

1. Manglani RP, Khaja M, Hennessey K, Kennedy O. Pleural mycobacterium avium complex infection in an immunocompetent female with no risk factors. Case Rep Pulmonol. 2015:760614.

2. Prince DS, Peterson DD, Steiner RM, Gottlieb JE, Scott R, Israel HL, et al. Infection with mycobacterium avium complex in patients without predisposing conditions. N Engl J Med. 1989;321:863-8.

3. Henry MT, Inamdar L, O'Riordain D, Schweiger M, Watson JP. Nontuberculous mycobacteria in non-HIV patients: epidemiology, treatment and response. Eur Respir J. 2004;23:741-6.

4. Martinez S, McAdams HP, Batchu CS. The many faces of pulmonary nontuberculous mycobacterial infection. AJR Am J Roentgenol. 2007;189:177-86.

5. Tortoli E. Clinical manifestations of nontuberculous mycobacteria infections. Clin Microbiol Infect. 2009;15:906-10.

6. Lim DH, Kim YG, Shim TS, Jo KW, Ghang B, Ahn SM, et al. Nontuberculous mycobacterial infection in rheumatoid arthritis patients: a single-center experience in South Korea. Korean $\mathrm{J}$ Intern Med. 2017;32:1090-7.

7. Phillips MS, von Reyn CF. Nosocomial infections due to nontuberculous mycobacteria. Clin Infect Dis. 2001;33:1363-74.

8. Daley CL. Nontuberculous mycobacterial infections. Eur Respir Mon. 2011;52:115-29.

9. Piersimoni C, Scarparo C. Extrapulmonary infections associated with nontuberculous Mycobacteria in immunocompetent persons. Emerg Infect Dis. 2009;15:1351-8.

10. Griffith DE. Epidemiology of nontuberculous mycobacterial infections Uptodate. [accessed 2017 Dec 11]. Available from https://www. uptodate.com/contents/epidemiology-of-nontuberculous-mycobacterialinfections

11. Marinho A, Fernandes G, Carvalho T, Pinheiro D, Gomes I. Nontuberculous mycobacteria in non-AIDS patients. Rev Port Pneumol. 2008;14:323-37. 
12. Dabó H, Santos V, Marinho A, Ramos A, Carvalho T, Ribeiro M, et al. Nontuberculous mycobacteria in respiratory specimens: clinical significance at a tertiary care hospital in the north of Portugal. J Bras Pneumol. 2015;41:292-4.

13. van Ingen J, Bendien SA, de Lange WC, Hoefsloot W, Dekhuijzen PN, Boeree $\mathrm{MJ}$, et al. Clinical relevance of non-tuberculous mycobacteria isolated in the Nijmegen-Arnhem region, The Netherlands. Thorax. 2009;64:502-6.

14. Griffith DE, Aksamit T, Brown-Elliott BA, Catanzaro A, Daley C, Gordin $F$, et al. An official ATS/IDSA statement: Diagnosis, treatment, and prevention of nontuberculous mycobacterial diseases. Am J Respir Crit Care Med. 2007;175:367-416.

15. Haworth CS, Banks J, Capstick T, Fisher AJ, Gorsuch T, Laurenson IF, et al. British Thoracic Society guidelines for the management of nontuberculous mycobacterial pulmonary disease (NTM-PD). Thorax. 2017;72:ii1-64.

16. Antunes A, Carvalho AC, Gonçalves AF, Ferreira B, Ribeiro C, Santos $\mathrm{CL}$, et al. Manual de Tuberculose e Micobactérias Não-Tuberculosas. Programa Nacional para a Tuberculose. 2013. [Accessed 2017 Dec 13].
Available from: https://www.dgs.pt/ficheiros-de-upload-2013/tb-manualde-tuberculose-e-micobacterias-nao-tuberculosas-pdf.aspx.

17. Field SK, Cowie RL. Lung disease due to the more common nontuberculous mycobacteria. Chest. 2006;129:1653-72.

18. Griffith DE. Overview of nontuberculous mycobacterial infections in HIV-negative patients. Uptodate. [Acessed 2017 Dec 11]. Available from: https://www.uptodate.com/contents/overview-of-nontuberculousmycobacterial-infections-in-hiv-negative-patients.

19. Jenkins PA, Campbell IA. Pulmonary disease caused by mycobacterium xenopi in HIV-negative patients: five year follow-up of patients receiving standardised treatment. Respir Med. 2003;97:439-44.

20. Henriques B, Hoffner SE, Petrini B, Juhlin I, Wåhlén P, Källenius G. Infection with mycobacterium malmoense in Sweden: report of 221 cases. Clin Infect Dis. 1994;18:596-600.

21. Somoskovi A, Mester J, Hale YM, Parsons LM, Salfinger M. Laboratory diagnosis of nontuberculous mycobacteria. Clin Chest Med. 2002;23:585-97.

22. Bailey WC. Treatment of atypical mycobacterial disease. Chest. 1983;84:625-8. 